$0.71 \mathrm{ng} / \mathrm{ml}(0.12-3.28, \mathrm{n}=217)$ and median $\mathrm{OC}$ was $28.2 \mathrm{ng} / \mathrm{ml}$ (6.80198.60, $\mathrm{n}=215$ ). Through univariate analysis, higher $\mathrm{bCL}$ values predicted worse survival outcome ( $\mathrm{HR}=3.09 ; 95 \% \mathrm{Cl}=1.14-8.39 ; \mathrm{p}=0.026)$, even after adjustment for age/sex (HR=4.28; 95\% $\mathrm{Cl}=1.48-12.29 ; \mathrm{p}=0.007)$; however, it did not predict higher risk of new fracture $(\mathrm{HR}=3.00 ; 95 \% \mathrm{Cl}=0.85-10.68$; $\mathrm{p}=0.089$ ). Serum $\mathrm{OC}$ levels showed no statistically significant results, neither for mortality $(\mathrm{HR}=1.01 ; 95 \% \mathrm{Cl}=0.99-1.03 ; \mathrm{p}=0.341)$ nor new fracture ( $\mathrm{HR}=1.01 ; 95 \% \mathrm{Cl}=0.99-1.04 ; \mathrm{p}=0.057)$.

Abstract AB0833 Table 1

\begin{tabular}{|c|c|}
\hline Total $(\mathrm{N})$ & 215 \\
\hline Age at admission, y (median, min-max) & $82(65-99)$ \\
\hline Sex, female $(n, \%)$ & $172,78.9$ \\
\hline $\mathrm{BMI}(\mathrm{N})$ & 195 \\
\hline Underweight $(n, \%)$ & $4,2.1$ \\
\hline Normal $(n, \%)$ & $90,46.2$ \\
\hline Overweight $(\mathrm{n}, \%)$ & $66,33.8$ \\
\hline Obesity class I (n,\%) & $29,14.9$ \\
\hline Obesity class II (n,\%) & $5,2.6$ \\
\hline Obesity class III $(n, \%)$ & $1,0.5$ \\
\hline Degree of dependence $(\mathrm{N})$ & 205 \\
\hline Totally dependent $(n, \%)$ & $10,4.9$ \\
\hline Partially dependent $(n, \%)$ & $53,25.9$ \\
\hline Autonomous ( $\mathrm{n}, \%)$ & $142,69.3$ \\
\hline Type of fracture $(\mathrm{N})$ & 217 \\
\hline Transtrochanteric $(n, \%)$ & $111,51.2$ \\
\hline Femoral neck $(n, \%)$ & $90,41.5$ \\
\hline Subtrochanteric $(n, \%)$ & $16,7.4$ \\
\hline Vertebral fracture $(\mathrm{N})$ & 213 \\
\hline $0(n, \%)$ & $92,43.2$ \\
\hline 1 fracture $(n, \%)$ & $53,24.9$ \\
\hline$\geq 2$ fractures $(n, \%)$ & $68,31.9$ \\
\hline Femur neck BMD, $\mathrm{g} / \mathrm{cm}^{2}$ (mean, SD, N) & $0.66,+-0.12,198$ \\
\hline Femur neck T score (mean, SD, N) & $-2.79,+-1.1,198$ \\
\hline$>2.5(n, \%)$ & $62,31.3$ \\
\hline$\leq 2.5(n, \%)$ & $136,68.7$ \\
\hline vitD, $\mathrm{ng} / \mathrm{ml}$ (median, min-max, N) & $23.24,3-97$ \\
\hline
\end{tabular}

Conclusion: In this cohort, increased serum levels of bCL predicted higher mortality risk. These results support the value of BTM in OP, strengthening their potential as prognostic markers, besides treatment monitors.

REFERENCE

[1] Glendenning P, Chubb SAP, Vasikaran S. Clin Chim Acta. 2018 Jun;481:161-170.

Disclosure of Interests: None declared

DOI: 10.1136/annrheumdis-2019-eular.632

\section{AB0834 FREQUENCY OF OSTEOPOROTIC HIP FRACTURE IN AN ALGERIAN HOSPITAL}

Naouel Zehraoui, Narimene Saidi, Houda Hafirassou, Chafia Makhloufi-Dahou Zehraoui Naouel Saidi Narimene Hafirassou Houda Chafia Dahou-Makhloufi. Mohamed Lamine Debaghine University Hospital, reumatology, algiers, Algeria

Background: The hip fracture is the most serious complication of osteoporosis. It is a public health issue in elderly because of its frequency, severity and economic impact. We report the result of an 18 months investigation.

Objectives: The aim of this study was to determine the frequency of osteoporotic hip fractures and identify the risk factors of osteoporosis and falls leading to these fractures.

Methods: Cross-sectional, prospective, descriptive study. Were included patients with spontaneous or secondary low trauma hip fractures during 18 months, who consulted at trauma unit, Mohamed Lamine Debaghine hospital. Have been collected: patient characteristics, risk factors for osteoporosis and falls, type of treatment and length of hospital stay.

Results: 115 cases of hip fractures were recorded out of a total of 486 fractures, with a frequency of $16.8 \%$, from all the fractures operated, it represents $22.7 \%$. We noted a female predominance $(62.6 \%)$ with a sex ratio of 0.60 , the average age is $76.44+/-11.71$ years. The associated comorbidities are: cardiovascular $(55.7 \%)$, diabetes $(33 \%)$, dysthyroidism $(11.4 \%)$, asthma $(10.4 \%)$, chronic renal failure $(5.2 \%)$ prostate adenoma $(4.5 \%)$. The fracture mechanism is dominated by the fall $(92 \%)$, it is most often a domestic accident: slipping (30\%), stumbling (26\%), ablution $(11 \%)$, falling on the stairs $(7 \%) . \%)$. The risk factors for osteoporosis identified are: age more than 70 years $(72.8 \%)$, female sex $(62.6 \%)$, low BMI $(18 \%)$, sedentary lifestyle $(15.3 \%)$, corticosteroid therapy $7.2 \%$, smoking $(6.3 \%)$, history of rheumatoid arthritis in $3.4 \%$ and early menopause in $2.1 \%$ of patients. The risk factors of fracture: visual disturbances $(40 \%)$ neuromuscular disorders in $11,9 \%$, poor health (more than 3 chronic diseases) in $9 \%$ of patients, mother's history of hip fracture (1.7\%). A personal history of osteoporotic fracture was noted in $17.4 \%, 7$ patients presented a contralateral hip fracture. The average duration of hospitalization is $5.2+/-2.5$ days. The treatment is surgical in $81.6 \%$ (40.8\% prostheses).

Conclusion: Through this study, we found that osteoporotic hip fracture is frequent. The osteoporosis risk factors identified were female sex advanced age, corticosteroid therapy and sedentary lifestyle. Fall risk factors were dominated by visual disturbances and neuromuscular disorders.

\section{REFERENCES}

[1] Charles M. Court-Brown, Ben Caesar. Epidemiology of adult fractures: A review. Injury 2006

[2] Desmond Curran. Épidémiologie des fractures liées à l'ostéoporose en France : revue de la littérature. Revue du rhumatisme 77 (2010) 579-585.

[3] Denise Grolimund Berset. Traumatologie de la personne âgée: une urgence nutritionnelle? Nutrition clinique et métabolisme 23 (2009) 129132

[4] Margaret stevens.preventing falls in older peoples: impact of an interventionto reduce environmental hazards in home. J Am Geratr Soc 2001; 49 1442-7.

Disclosure of Interests: None declared

DOI: 10.1136/annrheumdis-2019-eular.7819

\section{AB0835 BONE MINERAL LOSS DURING ULCERATIVE COLITIS : PREVALENCE AND RISK FACTORS}

Hela Kchir ${ }^{1}$, Maha Mtir ${ }^{2,2}$, Dhilel Issaoui ${ }^{2}$, Dhouha Cherif ${ }^{3}$, dhia kaffel $^{4}$, Nadia Maamouri'. ' 'La Rabta Hospital, Gastroebterology B, Tunis, Tunisia; ${ }^{2}$ La Rabta Hospital, Gastroenterology B, Tunis, Tunisia; ${ }^{3}$ La Rabta Hospital, Gastroenterology b, Tunis, Tunisia; ${ }^{4}$ Kassab institute, Rheumatology, Tunis, Tunisia

Background: Patients with ulcerative colitis (UC) are at increased risk of bone mineral loss, leading to osteoporosis and osteopenia. Etiopathogenetic factors may be divided into factors specific to the underlying inflammatory process, and factors resulting from the disease process, such as malabsorption of nutrients vitamins and minerals,decreases in weight,and the use of bone toxic medications.

Objectives: to evaluate the prevalence and possible risk factors for bone mineral density disorders in patients with UC.

Methods: A retrospective study from January 2000 to December 2018, including all patients with UC followerd in our department. Bone mineral density was determined by dual energy X-ray absorptiometry.

Results: Seventy eight patients were included in our study (36 men, 26 premenopausal, and 17 postmenopausal women) with an average age of 47.5 years. Forty osteodensitometries (DXA) were performed : 17 were normal ( $42.5 \%), 13$ patients had osteopenia (32.5\%) and 10 suffered from osteoporosis (25\%). Among the 23 patients having a bone mineral loss, the average Z-score were $(-0.8 \mathrm{SD})$ in the femoral neck and $(-1.78$ $\mathrm{SD}$ ) in the lumbar (L2-L4) spine whereas the average T-score were ($1.23 \mathrm{SD}$ ) in the femoral neck and $(-2.15 \mathrm{SD}$ ) in the lumbar (L2-L4) spine. Osteoporotic patients included 12 men, 5 premenopausal, and 6 postmenopausal women with an average age of 53.04 years. The research of risk factors has shown that 14 patients with bone minera loss $(60.86 \%)$ underwent systemic corticosteroid treatment with an average duration of 6 months. Tobacco intoxication has been mentioned in 8 cases $(34.78 \%$ ) and alcoholism in 6 cases $(26.08 \%)$. Otherwise, patients with bone mineral loss showed a lower body mass index (average BMl =19.46) than patients with normal bone density (average BMI $=23.64$ ). Anemia has been reported in 11 cases with low bone density (47.82\%) and low level of albumin as noted In 8 cases (34.78\%). No osteoporotic fractures has been reported. Pan-ulcerative Colitis was reported in 11 cases $(47.82 \%)$ and acute severe ulcerative colitis in 10 cases $(43.47 \%)$. Conclusion: Our study shows that more than half of our patients having ulcerative colitis (UC) who had an osteodensitometry presented bone demineralization (osteoporosis or osteopenia). It seems to be associated with a low BMI, an extended and severe form of UC, and the cumulative corticoid doses.

Disclosure of Interests: None declared

DOI: 10.1136/annrheumdis-2019-eular.8070 